\title{
Effect of Multivitamin and Amino Acid Supplementation on Average Daily Gain and Health Status in Cross-Bred Holstein Calves with Poor Growth Rates
}

Veerasak Punyapornwithaya, Paramintra Vinitchaikul*

Department of Food Animal Clinic, Faculty of Veterinary Medicine, Chiang Mai University, Mae Hia, Muang, Chiang Mai, 50100, Thailand.

\begin{abstract}
The objective of this study was to determine the effect of multivitamin and amino acid supplementation on average daily gain (ADG) in post-weaning dairy calves 4-7 months of age. Thirty-two cross-bred, post-weaning, female Holstein calves with ADG $<0.55 \mathrm{~kg} /$ day during the pre-weaning period were enrolled. Age-matched calves were divided equally into control and treatment groups. The treatment group was supplemented orally with $5 \mathrm{ml}$ of a multivitamin and amino acid supplement once daily. All calves were weighed on a digital scale at days0, 30, 60, and 90. A generalized least-squares method in the $\mathrm{R}$ statistical software package was used to compare ADG between the control and treatment groups. Treatment, time, and the interaction were fixed effects. Individual calves were assigned as random effect. The results revealed that the overall ADG was significantly higher $(P<0.05)$ in the treatment group than in the control group $(0.67 \pm 0.02 \mathrm{~kg}$ vs $0.56 \pm 0.04 \mathrm{~kg})$. When each month was examined individually, there was no significant difference $(P>0.05)$ in ADG between days 30 and 60. However, ADG was significantly higher $(P<0.05)$ in the treatment group than in the control group $(0.68 \pm 0.04 \mathrm{~kg}$ vs $0.49 \pm 0.06 \mathrm{~kg})$ at day 90 . In conclusion, the results strongly supported the hypothesis that multivitamin and amino acid supplementation effectively increase ADG after administration at day 90 and in the overall post-weaning period in cross-bred female Holstein calves 4-7 months of age with poor growth rates at pre-weaning.
\end{abstract}

Keywords | Multivitamins, Amino acids, Supplementation, ADG, Calve

Received | November 05, 2018; Accepted | December 19, 2018; Published | March 02, 2019

${ }^{*}$ Correspondence | Paramintra Vinitchaikul, Department of Food Animal Clinic, Faculty of Veterinary Medicine, Chiang Mai University, Mae Hia, Muang, Chiang Mai, 50100, Thailand; Email: pvinitchaikul@gmail.com

Citation | Punyapornwithaya V, Vinitchaikul P (2019). Effect of multivitamin and amino acid supplementation on average daily gain and health status in crossbred holstein calves with poor growth rates. Adv. Anim. Vet. Sci. 7(5): 335-339.

DOI | http://dx.doi.org/10.17582/journal.aavs/2019/7.5.335.339

ISSN (Online) | 2307-8316; ISSN (Print) | 2309-3331

Copyright (c) 2019 Punyapornwithaya and Vinitchaikul. This is an open access article distributed under the Creative Commons Attribution License, which permits unrestricted use, distribution, and reproduction in any medium, provided the original work is properly cited.

\section{INTRODUCTION}

$\mathrm{R}$ eplacement heifers are the keys to success in dairy farming, as they increase future dairy production potential. To achieve this, dairy farms would be concern along since young sucking calves until pregnant heifers preferably during weaning period. Intensive management is especially required in the 4-7 months age range. Particularly, post-weaning calves require $16 \%$ crude protein in their diets (NRC, 1996). This dietary protein is absorbed in the form of apparent amino acids from the small intestine and utilized by growing calves (Santos et al., 1984). Vitamins and minerals play a vital role for promoting daily bodily functions (MacDowell, 2012; Underwood and Suttle,
1999). Therefore, post-weaning calves must receive these nutrients from their forage and a commercial replacer or concentrated diet.

Even the rumen microbial flora is a rich source of vitamins (Hill, 1997). The rumen does not become functional with respect to vitamin synthesis for some time after birth. For the first few day of life the young calves resemble a non-ruminant in requiring dietary source of the vitamins (Davis and Drackley, 1998; MacDowell, 2012). Moreover, numerous vitamins and minerals cannot be synthesized by the animal itself; therefore, dietary supplementation in necessary to achieve the daily requirement (Spears and Weiss, 2014). Furthermore, absorption and utilization are highly 
Table 1: The composition of multivitamins and amino acids per liter

\begin{tabular}{|c|c|c|c|c|c|}
\hline & Concentration & Unit & & Concentration & Unit \\
\hline Multivitamins & & & Amino Acids & & \\
\hline Vitamin A & $6,000,000$ & $\mathrm{IU}$ & Aspartic & 10.7 & $\mathrm{~g}$ \\
\hline Vitamin $\mathrm{D}_{3}$ & $2,000,000$ & IU & Threonine & 6.2 & $\mathrm{~g}$ \\
\hline Vitamin E & 3,000 & $\mathrm{IU}$ & Serine & 8.0 & $\mathrm{~g}$ \\
\hline Vitamin $B_{1}$ & 1.0 & $\mathrm{~g}$ & Glutamic & 18.4 & $\mathrm{~g}$ \\
\hline Vitamin $\mathrm{B}_{2}$ & 2.8 & $\mathrm{~g}$ & Proline & 6.2 & $\mathrm{~g}$ \\
\hline Vitamin $\mathrm{B}_{6}$ & 0.4 & $\mathrm{~g}$ & Glycine & 7.1 & $\mathrm{~g}$ \\
\hline Vitamin $B_{12}$ & 10.0 & $\mathrm{mg}$ & Alanine & 7.7 & $\mathrm{~g}$ \\
\hline Vitamin C & 3.0 & $\mathrm{~g}$ & Cysteine & 1.8 & $\mathrm{~g}$ \\
\hline Vitamin $\mathrm{K}_{3}$ & 3.0 & $\mathrm{~g}$ & Valine & 8.3 & $\mathrm{~g}$ \\
\hline Nicotinamide & 15.0 & $\mathrm{~g}$ & Methionine & 2.1 & $\mathrm{~g}$ \\
\hline Folic acid & 0.1 & $\mathrm{~g}$ & Isoleucine & 5.7 & $\mathrm{~g}$ \\
\hline \multirow[t]{6}{*}{ D Panthenol } & 8.0 & $\mathrm{~g}$ & Leucine & 9.5 & $\mathrm{~g}$ \\
\hline & & & Phenylalanine & 5.7 & $\mathrm{~g}$ \\
\hline & & & Tyrosine & 3.6 & $\mathrm{~g}$ \\
\hline & & & Lysine & 9.2 & $\mathrm{~g}$ \\
\hline & & & Histidine & 2.4 & $\mathrm{~g}$ \\
\hline & & & Arginine & 6.2 & $\mathrm{~g}$ \\
\hline
\end{tabular}

Table 2: Nutritional values of feed ingredients

\begin{tabular}{llllll} 
Feed & Dry Matter (\%) & Crude Protein (\%) & NDF (\%) & ADF (\%) & TDN (\%) \\
\hline Para grass & 22.6 & 8.0 & 66.8 & 37.8 & 56.0 \\
Rice straw & 88.8 & 3.6 & 68.8 & 42.3 & 44.0 \\
Commercial concentrate diet & 90.0 & 16.0 & - & - & 70.0
\end{tabular}

$\mathrm{NDF}=$ Neutral Detergent Fiber, ADF $=$ Acid Detergent Fiber,

TDN $=$ Total Digestible Nutrients

Source: Department of Livestock Development Knowledge Management, Thailand (2009)

dependent on the characteristics of individual calves. Because the rumen epithelium is constituted by papillae, a structure that enables absorption and utilization of the fermentation end-products, and its development is stimulated by the most varies abundant produced in the rumen ( $\mathrm{Ta}-$ mate et al., 1962).

Eventually, the nutrient intakes of post-weaning calves may not be sufficient to meet their growing demands. Oral multivitamin and amino acid supplements for post-weaning calves are efficient absorption at the small intestine (Sejrsen et al., 2006). Moreover, the gastro-intestinal tract is the first line of defense of the immune system. Therefore, nutritional functions of calves may improve the resistance to gastro-intestinal diseases (Ballou, 2013). This alternative route may allow calves, especially during rumen development, illness, consumption of a low-quality feed, and period of poor growth, to derive the nutrients they require from supplementation.

The growth rates, expressed as average daily gain (ADG), of cross-bred Holstein calves in Thailand are generally poor. Chamsawat and Moonkhaew (2012) reported that the ADG of cross-bred Holstein calves in Thailand varied from 0.52 to $0.60 \mathrm{~kg} /$ day, depending on the duration of feeding with milk replacer until weaning, whereas the lower and upper of ADGs for Holstein replacement calves at 4-7 months of age under ideal management would be $0.77-0.82 \mathrm{~kg} / \mathrm{day}$ (Patrick, 2018). Therefore, the objective of this study was to determine the efficiency of administration of oral multivitamins and amino acids as a supplement for cross-bred Holstein calves at 4-7 months of age under poor growth rate conditions.

\section{MATERIALS AND METHODS}

\section{Animals, Design, and Feeding}

All animal care and experimental protocols were approved by the Laboratory Animal Ethics Committee, Faculty of Veterinary Medicine, Chiang Mai University (Ref No: S2/2558). The field trial was designed as a matched pair design by matching calves by age in order to control the 
effect of age. The required sample size was calculated by using $G$ power software program with repeated measurement design. The power of the test was set to 0.8 , and the $\alpha$ value was 0.05 . The results indicated that the experiment required at least 14 calves in each group. Therefore, a total of 32 cross-bred, post-weaning, female Holstein calves 4-7 months of age were included in this study. Matched couple calves were randomly assigned to two groups, 16 calves per each group, a control group and a treatment group. Moreover, all calves enrolled this study were required to have an ADG lower than $0.55 \mathrm{~kg} /$ day during the pre-weaning period.

The treatment group was supplemented orally with $5 \mathrm{ml}$ of multivitamins and amino acids once daily in the morning by using a syringe in the inter dental space. The trial lasted for 90 consecutive days. The composition of the multivitamin and amino acid supplement is presented in Table 1. The experimental calves were kept on the same farm under the same feeding, management, and environmental conditions. The study calves were group together and separately between the control and treatment groups in large, openair stalls without bedding.

Calves were fed according to the nutritional requirements outlined by the Department of Livestock Development, based on their body weight. The basal diets, consisting of freshly cut para grass and rice straw, were ad libitum fed. The commercially concentrated diet was separated into equal portions and fed twice daily in the morning and evening at $2 \mathrm{~kg} / \mathrm{calf} / \mathrm{day}$. The nutritional values of the feed ingredients given to calves are shown in Table 2. The animals had free access to drinking water during the whole experimental period. Changes in feeding management were not allowed in either experimental group. This experiment was conducted during dry season (March-August). The experimental farm was far away from other buildings but surrounded by grass land and corn field. The average temperature ranged from 28 to $35^{\circ} \mathrm{C}$ with humidity between 60 to $90 \%$.

\section{Data Collection}

Body weight was measured at $0,30,60$, and 90 days by using an automatic digital balance. To calculate ADG, the following formula was used:

$\mathrm{ADG}(\mathrm{kg} / \mathrm{day})=$
current body weight $(\mathrm{kg})-$ previous body weight $(\mathrm{kg})$
the number of days between the two measurements (days)

Any significant health problems in the experimental calves were recorded by the farm`s staff every day.

\section{Statistical Analysis}

The data for each calf were correlated; therefore, a generalized least-square (GLS) method in the R statistical soft- ware program with the "nlme" package was used to compare ADG between the treatment and control groups. The statistical model included treatment, time, and interaction between treatment and time as fixed effects. Individual calves were defined as a random effect.

The GLS model was constructed to test for the overall effect of treatment on ADG for the whole study (ADG calculated from day 1 to day 90). Linear contrasts were performed to analyze the data for specific time points including ADG at day 30, day 60, and day 90.To find the best fit model, GLS models were constructed with different correlation matrixes, including auto-regressive 1 (ar1), compound symmetry, and general symmetry. Then, Akaike's Information Criteria (AIC) from each model were compared. The model with the lowest AIC was suggested as the best fit model. Finally, the ar1 structure had the lowest AIC; therefore, results from the GLS with the ar1 correlation matrix were used to draw conclusions. In addition, residuals from the model were tested for model assumptions such as normality and homogeneity of variance. For all statistical analyses, the level of significance was set at $\alpha=0.05$.

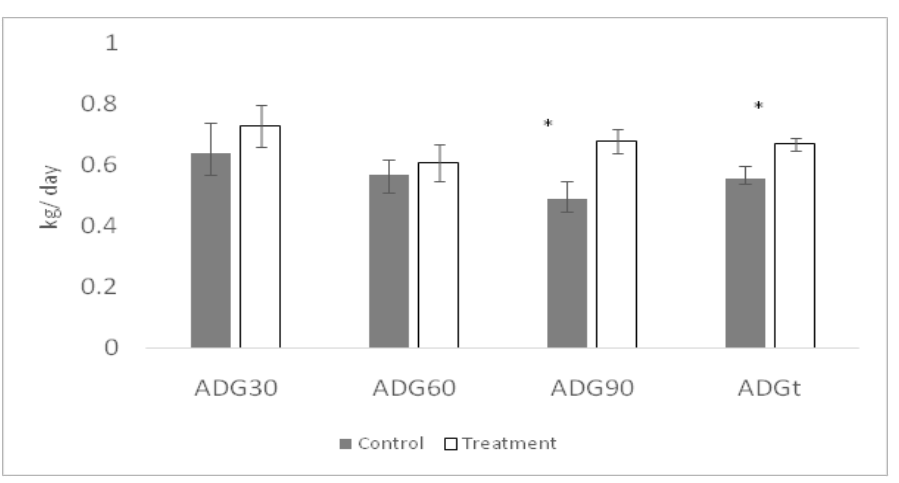

* Mean values were significantly different $(P<0.05)$

ADG30 = average daily gain at day 30,

ADG60 = average daily gain at day 60 ,

ADG90 = average daily gain at day 90 ,

ADGt $=$ overall average daily gain between day a 1 and 90

Figure 1: Effect of multivitamin and amino acid supplementation on average dairy gain (ADG) at days 30, 60, and 90 and on overall ADG (days 1-90) in cross-bred, post-weaning, female Holstein calves 4-7 months of age with $\mathrm{ADG}<0.55 \mathrm{~kg} /$ day during the pre-weaning period $(\mathrm{n}=32)$.

\section{RESULTS}

Mean initial body weight did not differ significantly between the control and treatment groups, indicating no confounding effect of the individual animals used at the beginning of the experiment. No interaction effect between treatment and time was found. The only effects on the ADG were those of multivitamin and amino acid sup- 
plementation and time in each month of the experimental period.

Regarding Figure 1, ADG at day 90 was significantly higher $(P<0.05)$ in the treatment group than in the control group $(0.68 \pm 0.04 \mathrm{~kg}$ vs $0.49 \pm 0.06 \mathrm{~kg})$. Moreover, the overall ADG from day 1 until day 90 in the treatment group was also significantly higher $(P<0.05)$ than in the control group $(0.67 \pm 0.02 \mathrm{~kg}$ vs $0.56 \pm 0.04 \mathrm{~kg})$. However, there was no significant difference $(P>0.05)$ in ADG between the treatment and control groups at day 30 and day 60 . In addition, there were no clinical health problems in any of the calves in either group during the study.

\section{DISCUSSION}

The results of this study indicate that using multivitamin and amino acid supplementation for cross-bred, post-weaning, female Holstein calves 4-7 month of age with poor grow rates, defined as an ADG $<0.55 \mathrm{~kg} /$ day during the pre-weaning period, improved ADG at day 90 and overall ADG from days 1 to 90 . Vitamins are important components that support many functions in growing calves. Multivitamin supplementation may enhance dry matter intake (Salinas-Chavira et al., 2014) and, correspondingly, ADG in calves with poor growth rates. Most often, vitamin A is of primary importance because most cattle from growth to finishing consume conserved forage and high-grain diets that are low in vitamin A (Hersom and Thrift, 2017). Our multivitamin supplementation was rich in vitamin $A$ and could be enriched in a nutritional value as well.

While, vitamin E supplementation alone in calf-fed Holstein steers was not expected to enhance their feed lot growth performance due to health status may be a factor in short-term responses to vitamin $\mathrm{E}$ supplementation (Cano et al., 2017). However, our trial study lasted up to 90 days and this period may enough for showed response effectiveness. In addition, feeding additional vitamin $\mathrm{E}$ as an antioxidant during in the summer season may needed due to reduce oxidative stress (Nayyar and Jindal, 2010).

The rumen in a dairy calf at 4-7 months of ages is not yet fully developed, having a small ruminal capacity, low absorptive capacity, and low population of microorganisms. Directly supplemented amino acids were efficiently absorbed, as they passed via the small intestine and were absorbed by the intestinal tissues. This method of supplementation may improve amino acid availability to support growth performance (Baldwin et al., 2004). Moreover, this supplementation promoted the effective functional performance of microbial organisms in the rumen (Maeng et al., 1976). In addition, Kanjanapruthipong (1998) and Hill et al. (2008)suggested that ADG was improved by adding ly- sine, methionine and/or threonine to milk replacer.

There was no significant difference in ADG between the control and treatment groups at days 30 and 60 of the early experimental period. Several causes of this are possible, such as genetics, stress, the season, and subclinical diseases (Galyean et al., 1999; Duff and Galyean, 2007). However, the main effects of ADG are the components of animal diets, including forage, grain, minerals, vitamins, and feed additives (Parish, 2013). Moreover, the calves in this study had moved from different free-stall barns and were kept together once the experiment started. This may have stimulated stress from the change in environment and feed source and composition, which may have augmented the risk of subclinical diseases during the early phase of the experiment.

The calves in our experiment came from various small holder dairy farms with uncontrollable pre-weaning practices. Pre-weaning managementis a critical factor that affects calf growth performance (Step et al., 2008). This factor may have affected the growth performance of post-weaning calves. However, ADG at day 90 and overall ADG in the multivitamin and amino acid supplementation groups were clearly higher than those in the control group. Because multivitamin and amino acid supplementation were used sufficient successful for conditioning during late experimental period and were more encouraged growth performance. This finding suggested that if one would like to enhance the growth performance of dairy calves, the longterm uses of multivitamin and amino acid should be considered.

In conclusion, the results strongly support the hypothesis that multivitamin and amino acid supplementation effectively increase ADG at day 90 and overall ADG in crossbred post-weaning female Holstein calves a 4-7 months of age with poor growth rates. This field trial suggested an alternative management method to improve the growth rates of calves with poor growth performance on a dairy farm.

\section{ACKNOWLEDGEMENTS}

The authors are grateful to Bayer Thai Co., Ltd. for providing the multivitamins and amino acids. This research grant was supported by Faculty of Veterinary Medicine, Chiang Mai University. The authors are also thankful to the staff of the heifer replacement farm, Faculty of Agriculture, Chiang Mai University for assistant in our study.

\section{CONFLICT OF INTEREST}

We would like to declare the following study had no con- 
flict of interest situation.

\section{AUTHORS CONTRIBUTION}

Veerasak Punyapornwithaya designed the study, conducted the experiment, analysed data and reviewed the manuscript. Paramintra Vinitchaikuldesigned the study, prepared and revised the manuscript.

\section{REFERENCES}

-Baldwin RL, McLeod KR, Klotz JL, Heitmann RN (2004). Rumen development, intestinal growth and hepatic metabolism in the pre-and post weaning ruminant. J. Dairy Sci. 87: 55-65. https://doi.org/10.3168/jds.S00220302(04)70061-2

- Ballou MA (2013). Enhancing Calf Immunity through Nutrition. Texas Tech University, Lubbock, TX, USA.

- Cano AB, Montano M, Salinas-Chavira J, Zinn RA (2017). Evaluation of supplemental vitamin E on 56-day feedlot growth performance and plasma tocopherol concentrations in calf-fed Holstein steers. J. Appl. Anim. Res. 45(1): 90-92. https://doi.org/10.1080/09712119.2015.1129340

- Champely S (2015). Basic Function for Power analysis. [online]. Available: http://cran.r-project.org/package=pwr.

- Chamsawat V, Moonkhaew S (2012). Research for improvement of dairy replacement heiferby calves feeding system. [Online]. Available: http://old.rmutto.ac.th/fileupload/ Wannasa\%20Balsong6vol5-1-011.pdf

- Cohen J (1988). Statistical power analysis for the behavioral sciences. Lawrence Erlbaum Associates, USA.

-Davis CL, Drackley JK (1998). The development, nutrition, and management of the young calf. Iowa State University Press, USA.

-Department of Livestock Development Knowledge Management, Thailand (2009). The nutrition value of feed ingredients. [Online]. Available: http://km.dld.go.th/th/ index.php/th/research-system/knowledge-office/149kmproduction-cat/159-2009-12-24-03-18-19

-Duff GC, Galyean ML (2007). Board-invited review: recent advances inmanagement of highly stressed, newly received feedlot cattle. J. Anim. Sci. 85(3): 823-840. https://doi. org/10.2527/jas.2006-501

- Galyean ML, Perino LJ, Duff GC (1999). Interaction of cattle health/immunity and nutrition. J. Anim. Sci. 77(5): 11201134. https://doi.org/10.2527/1999.7751120x

- Hersom M, Thrift T (2017). Growing calf and show steer feed management. [Online]. Available: http://edis.ifas.ufl.edu/ an 254.

- Hill MJ (1997). Intestinal flora and endogenous vitamin synthesis. Eur. J. Cancer Prev. 6(2): 43-45. https://doi. org/10.1097/00008469-199703001-00009

-Hill TM, Bateman HG, Aldrich JM, Schlotterbeck RL, Tanan KG (2008). Optimal concentrations of lysine, methionine, and threonine in milk replacers for calves less than five weeks of age. J. Dairy Sci. 91(6): 2433-2442. https://doi. org/10.3168/jds.2007-0610
-Kanjanapruthipong J (1998). Supplementation of milk replacers containing soy protein with threonine, methionine, and lysine in the diets of calves. J. Dairy Sci. 81(11): 2912-2915 https://doi.org/10.3168/jds.S0022-0302(98)75852-7.

-McDowell LR (2012). In: Vitamins in animal nutrition: comparative aspects to human nutrition. Elsevier, 2012.

-Maeng WJ, Van Nevel CJ, Baldwin RL, Morris JG (1976). Rumen microbial growth rates and yields: Effect of amino acids and protein1. J. Dairy Sci. 59(1): 68-79. https://doi. org/10.3168/jds.S0022-0302(76)84157-4

- National Research Council (NRC), Subcommittee on Dairy Cattle Nutrition. 1978. Nutrient requirements of dairy cattle/Subcommittee on Dairy Cattle Nutrition, Committee on Animal Nutrition, Board on Agriculture and Renewable Resources, National Research Council. $5^{\text {th }}$ rev. ed. Washington: National Academy of Sciences, USA.

- Nayyar S, Jindal R (2010). Essentiality of antioxidant vitamins for ruminants in relation to stress and reproduction. Iran J. Vet. Res.11(1): 1-9.

- Parish J (2013). Putting Average Daily Gain in Context. [Online]. Available: http://www.cattlenetwork.com/cattlenews/Putting-average-daily-gain-in-context-200495801. html.

- Patrick CH, (2018). Optimum growth rates for Holstein replacement heifers. [Online]. Available:https://fyi.uwex. edu/heifermgmt/files/2015/02/optimumgrowthrates.pdf

-Santos KA, Stern MD, Satter LD (1984). Protein degradation in the rumen and amino acid absorption in the small intestine of lactating dairy cattle fed various protein sources. J. Anim. Sci. 58(1): 244-255. https://doi.org/10.2527/ jas1984.581244x

- Salinas-Chavira J, Arrizon AA, Barreras A, Chen CZ, Plascencia A, Zinn RA (2014). Evaluation of supplemental vitamin $\mathrm{A}$ and $\mathrm{E}$ on 56-day growth performance, dietary net energy, and plasma retinol and tocopherol concentrations in Holstein steer calves. Prof. Anim. Scientist. 30(5): 510-514 https://doi.org/10.15232/pas.2014-01316.

-Sejrsen K, Hvelplund T, Nielsen MO (2006). In: Ruminant physiology: digestion, metabolism and impact of nutrition on gene expression, immunology and stress. Wageningen Academic Pub. https://doi.org/10.3920/978-90-8686-566-

-Step DL, Krehbiel CR, DePra HA, Cranston JJ, Fulton RW, Kirkpatrick JG, Confer AW (2008). Effects of commingling beef calves from different sources and weaning protocols during a forty-two-day receiving period on performance and bovine respiratory disease. J. Anim. Sci. 86(11): 3146-3158 https://doi.org/10.2527/jas.2008-0883.

- Spears JW, Weiss WP (2014). Invited review: Mineral and vitamin nutrition in ruminants. Prof. Anim. Scientist. 30(2): 180-191. https://doi.org/10.15232/S1080-7446(15)301030

- Tamate H, McGilliard AD, Jacobson NL, Getty R (1962). Effect of various dietaries on the anatomical development of the stomach in the calf.J. Dairy. Sci. 45:408-420. https://doi. org/10.3168/jds.S0022-0302(62)89406-5

-Underwood EJ, Suttle NF (1999). In: The mineral nutrition of livestock 3rd Ed. CABI Publishing, CAB International, Wallingford, and Oxon, UK. 